\title{
Social networking sites addiction and associated psychological problems among young adults: A study from North India
}

\author{
PS Meena, R Soni, M Jain, S Paliwal
}

\section{Background}

The world is ever changing due to advancements in the realms of science and technology, with one such advancement being in the field of social networking. The ubiquity of social networking sites (SNSs) raises the concern for its problematic use among young adults and its relationship with mental health problems.

\section{Objectives}

The aim of the study was to explore the prevalence of social networking sites addiction and associated psychological problems in young adults.

\section{Methods}

Across-sectional descriptive study involving 200 medical students of Jawahar Lal Nehru Medical College, Ajmer was conducted to assess SNS addiction with a semi-structured proforma. The Depression Anxiety Stress scale-21 (DASS-21) and General Health
Questionnaire-12 (GHQ-12) were used to assess participant's psychosocial status.

\section{Results}

Out of 197 participants who completed the questionnaires 83 students $(42.1 \%)$ were mildly effected, while 108 (54.8\%) and 6 (3\%) students were moderately and severely addicted to SNSs. Those with excessive SNSs use had higher rates of depression, anxiety and stress scores.

\section{Conclusion}

The findings of this study indicate that excessive SNSs use among students is associated with increased psychological symptoms, including symptoms of stress and anxiety. Further research is needed to explore these associations further.

Key words: social networking sites, Young's internet addiction scale, Facebook addiction

SL J Psychiatry 2015; 6(1): 14-16

\section{Introduction}

The world is ever changing due to the advancements in the domains of science and technology. The ways in which people interact with each other has changed dramatically with these advancements and social network sites (SNSs) is one such example.

"Social Networking Sites are virtual communities where users can create individual public profiles, interact with real-life friends and meet other people based on shared interests" (1). SNSs have recorded phenomenal growth rates worldwide over the last few years. A recent survey indicated that in 2009, an average online social-network user spent more than $5 \frac{1}{2} \mathrm{~h}$ per month on social networking sites, which was triple the time spent on other online activities (2). From April 2008 to April 2009, the total minutes spent on Facebook in the U. S. has shown $700 \%$ annual growth from 1.7 billion minutes to 13.9 billion minutes (2). These statistics alone indicate the exponential rise of SNSs and also suggests potential for addiction.

In the first decade of the $21^{\text {st }}$ century, mental health professionals began to recognise problematic use of
SNSs as psychological disorder. Young adults may not realise how much of time they spent on SNSs and its negative effect on their academic performance, employment, real life social community participation and relationship problems. Each of these may be indicative of potential addiction. It is now justified to label SNSs addiction as a behavioural addiction because addiction criteria, such as neglect of personal life, mental preoccupation, escapism, mood modifying experiences, tolerance, and concealing the addictive behaviour appear to be present in some people who use SNSs excessively (3). Therefore it is important to study the concept of the technological dependency pattern of SNSs usage in young adults and its relationship with their mental health.

\section{Methods}

A cross-sectional descriptive study was conducted at Jawahar Lal Nehru Medical College, Ajmer, India in September and October 2014. The study sample consisted of 200 medical students aged between 21-25 years; the participants were selected using simple random sampling method with representation from all batches. 
Information was gathered from the participants through a questionnaire which included questions on demographics, purpose of using SNSs, place of access and average duration of use per day.

The following scales were also used in gathering information. Young's internet addiction scale (YIAS) was used to asses for features of possible internet addiction. This is a 20-item 5-point Likert scale that measures the severity of self-reported compulsive use of the social networking sites on internet. Total YAIS scores are calculated, with possible scores for the sum of 20 items ranging from 20 to 100 . The scale has good internal consistency, with an alpha coefficient of 0.93 (4). The Depression, Anxiety and Stress scale-21 (DASS 21), a 21 item self-report questionnaire was used to screen for presence of symptoms of depression, anxiety and stress (5). The General Health Questionnaire 12 item version (GHQ-12) was used to screen for possible presence of psychological distress among participants. It has good internal consistency in terms of Cronbach's alpha scores of .82 to $.86(6)$.

Fisher's exact test for significance, unpaired t-test and Pearson's correlation coefficient were used to analyse the data. The study was conducted after obtaining approval from the Institutional Review Board and permission was sought from the relevant college authorities.

\section{Results}

Of the 200 students to whom the questionnaires were distributed, 197 students returned the completed questionnaires. Thus, a total of 197 students were included in the study, of whom $61.9 \%(n=122)$ were males. The mean age of participants was 21 years $(S D=1.4$ years).

Based on the total YIAS scores, 42.1\% $(n=83)$ participants were average users (YAIS score 20-49), 54.8\% (n=108) were over users (YAIS scores $50-79)$, and $3 \%(n=6)$ met YAIS criteria for addiction (YAIS scores 80-100). No significant difference was found in YAIS scores between male and female participants.

Of the participants, $23.8 \%(n=47)$ had GHQ scores suggestive of distress $(>15)$ and $4 \%(n=8)$ had evidence of severe psychological distress (GHQ scores $>20$ ). Males were significantly more likely than females to have GHQ scores indicative of psychological distress $(\mathrm{p}=0.02)$.

Analysis of the DASS-21 indicated that $26.9 \%(n=53)$ of participants met criteria for mild depression while $21.8 \%$ $(\mathrm{n}=87)$ and $8.1 \%(\mathrm{n}=32)$ had moderate and severe depression respectively. Mean depression sub scores of male participants were significantly higher than that of females $(\mathrm{p}=0.01)$. Anxiety sub scores of DASS-21 indicated that $21.8 \%(n=43)$ had mild anxiety while $41.1 \%$
( $n=81), 20.2 \%(n=41)$ and $5 \%(n=10)$ of participants met criteria for moderate, severe and very severe anxiety categories respectively. The mean anxiety sub score of male participants was significantly higher than that of the females $(p=.01)$. The results of the stress sub scale of the DASS-21 suggested that $41.1 \%(n=81)$ of participants had mild stress, while $32.9 \%(n=65)$ and $7.1 \%(n=14)$ had moderate and severe stress respectively. The mean stress sub scores of male participants was significantly higher than that of females $(\mathrm{p}=.02)$.

Strong correlations were found between the mean YIAS scores and GHQ scores $(\mathrm{r}=0.56)$ and between the YIAS scores and DASS depression sub score $(\mathrm{r}=0.51)$, anxiety sub score $(\mathrm{r}=0.69)$ and stress sub scores $(\mathrm{r}=0.74)$.

\section{Discussion}

There is a dearth of information about SNSs addiction in this part of the world. The findings this study provides important information regarding the extent of SNSs addiction among University students in India and South Asia.

Machold et al in their study on social networking patterns and hazards among Irish teenagers described findings similar to that of this study, indicating possible risks of SNSs overuse and associated problems (7). In our study there was no significant difference in SNS overuse between males and females. This is in contrast to previous data which have reported SNS overuse to be significant higher among school boys when compared to girls (8). A previous study has described a significant association between time spent on SNS and depressionin high school students, which is similar to the findings in this study (9). However, Jelenchick et al did not find evidence supporting a relationship between SNS use and clinical depression in older adolescent's (10). Further, in this study we found a significant correlation between YIAS scores and levels of stress and anxiety.

\section{Limitations}

This study was conducted among a group of medical students, and so cannot be directly generalised to all young adults. Secondly, the presence of depression, anxiety and stress among participants in this study may be attributable to factors other than SNS use; it is not possible to make a causal association with SNS use, given the descriptive nature of the study.

\section{Conclusions}

Despite the above limitations, the findings of this study suggest that excessive SNSs use among young people may be associated with symptoms psychological distress. With increasing popularity of SNSs, in spite of its utility, young adults need be aware about its potential adverse effect on mental health. Further research is needed to explore these hypothesis further, particularly in South Asia. 


\section{Declaration of interest}

None declared

PS Meena, R Soni, M Jain, S Paliwal, Department of Psychiatry, JLN Medical College, Ajmer, India

Corresponding author: R Soni

Email: dr.ruchi07@gmail.com

\section{References}

1. Boyd DM, Ellison NB. Social network sites: Definition, history, and scholarship. J Comput Mediat Comm. 2007; 13: 210-30.

2. Kazeniac A. Social Networks: Facebook takes over top spot, twitter climbs. Compete Pulse. Available from: https://blog.compete.com/2009/02/09/facebook-myspacetwitter-social-network/ (accessed on 2010 Jun 8).

3. Young KS. Internet addiction: The emergence of a new clinical disorder. Cyber Psychol Behaviour 1998; 1(3): 237-44.
4. Widyanto L, McMurran M. The psychometric properties of the internet addiction test. Cyber Psychol Behaviour 2004; 7(4): 443-50.

5. Lovibond, SH, Lovibond, PF Manual for the Depression Anxiety Stress Scales. $2^{\text {nd }}$ ed. Sydney: Psychology Foundation; 1995.

6. Goldberg D, William P. A User's Guide to General Health Questionnaire. Windsor, Berkshire: NFER-Nelson; 1988.

7. Machold C, Judge G, Mavrinac A, Elliott J, Murphy AM, Roche E. Social networking patterns/hazards among teenagers. Ir Med J 2012; 105(5): 151-2.

8. Meena PS, Mittal PK, Solanki RK. Problematic use of social networking sites among urban school going teenagers. Ind Psychiatry J 2012; 21(2): 94-7.

9. Pantic I, Damjanovic A, Todorovic J, Topalovic D, Bojovic-Jovic D, Ristic S, Pantic S. Association between online social networking and depression in high school students: behavioral physiology viewpoint. Psychiatria Danubina 2012; 24(1): 90-3.

10. Jelenchick LA, Eickhoff JC, Moreno MA. “Facebook depression?” social networking site use and depression in older adolescents. J Adolesc Health 2013; 52(1): 128-30. 